\title{
Global plagues and the Global Fund: Challenges in the fight against HIV, TB and malaria
}

\author{
Darrell HS Tan*1, Ross EG Upshur ${ }^{2}$ and Nathan Ford ${ }^{3}$
}

\begin{abstract}
Address: ${ }^{1}$ Department of Medicine, University of Toronto. University Health Network, Toronto General Hospital Site, R. Fraser Elliott Building 3 Suite 805, 190 Elizabeth St, Toronto, Ontario, M5G 2C4, Canada, 2Primary Care Research Unit, Sunnybrook and Women's College Health Sciences Centre, Departments of Family and Community Medicine and Public Health Sciences, Joint Centre for Bioethics, University of Toronto. Room E349B, 2075 Bayview Avenue, Toronto, Ontario, M4N 3M5, Canada and ${ }^{3}$ Médecins Sans Frontières, 67-74 Saffron Hill, London EC1N 8QX, United Kingdom

Email: Darrell HS Tan* - darrell.tan@utoronto.ca; Ross EG Upshur - rupshur@idirect.com; Nathan Ford - Nathan_FORD@msf.org

* Corresponding author
\end{abstract}

Published: I April 2003

BMC International Health and Human Rights 2003, 3:2

This article is available from: http://www.biomedcentral.com/I 472-698X/3/2

C 2003 Tan et al; licensee BioMed Central Ltd. This is an Open Access article: verbatim copying and redistribution of this article are permitted in all media for any purpose, provided this notice is preserved along with the article's original URL.
Received: 12 November 2002

Accepted: I April 2003

\begin{abstract}
Background: Although a grossly disproportionate burden of disease from HIVIAIDS, TB and malaria remains in the Global South, these infectious diseases have finally risen to the top of the international agenda in recent years. Ideal strategies for combating these diseases must balance the advantages and disadvantages of 'vertical' disease control programs and 'horizontal' capacitybuilding approaches.
\end{abstract}

Discussion: The Global Fund to Fight AIDS, Tuberculosis and Malaria (GFATM) represents an important step forward in the struggle against these pathogens. While its goals are laudable, significant barriers persist. Most significant is the pitiful lack of funds committed by world governments, particularly those of the very G8 countries whose discussions gave rise to the Fund. A drastic scaling up of resources is the first clear requirement for the GFATM to live up to the international community's lofty intentions. A directly related issue is that of maintaining a strong commitment to the treatment of the three diseases along with traditional prevention approaches, with the ensuing debates over providing affordable access to medications in the face of the pharmaceutical industry's vigorous protection of patent rights.

Summary: At this early point in the Fund's history, it remains to be seen how these issues will be resolved at the programming level. Nevertheless, it is clear that significant structural changes are required in such domains as global spending priorities, debt relief, trade policy, and corporate responsibility. HIVIAIDS, tuberculosis and malaria are global problems borne of gross socioeconomic inequality, and their solutions require correspondingly geopolitical solutions.

\section{Background}

World Health Organization (WHO) statistics estimate that over 5.6 million people are killed by HIV/AIDS, tuberculosis and malaria every year, with virtually all of these deaths occurring in the developing world [1]. This virus, bacterium and parasite are the top infectious disease killers in the world today. While the morbidity and mortality stemming from the latter two agents have devastated populations for centuries, the HIV/AIDS pandemic has helped stimulate a recent surge of high-level interest in infectious disease control launching all three diseases to the forefront of public attention over just a few short years. 
Out of the growing momentum over these diseases has emerged a potentially golden opportunity, in the form of the new Global Fund to Fight AIDS, Tuberculosis and Malaria (GFATM). Its creation demonstrates a significant step forward, though important policy issues remain to be worked out. What specific strategies will allow us to successfully generate and maintain the global public good of AIDS, tuberculosis and malaria control?

This paper will discuss the GFATM and important priorities for the control of these diseases. An overview of the policy context is presented first, discussing the reasons for the recent surge of interest in these diseases and outlining two general ways of conceptualizing disease control: 'vertical', disease-specific control programs, and 'horizontal', broader-based approaches. A brief analysis of the GFATM's initial round of grants follows, examining its balance between vertical and horizontal approaches, as well as between treatment and prevention. Finally, the paper describes the major obstacles to the GFATM's success - namely, that of funding - and identifies specific political and economic strategies for the international community regarding the control of these diseases in the future.

\section{Why All the Interest?}

It has long been recognized that infectious diseases constitute a significant global burden of disease. In 2001, HIV/ AIDS, tuberculosis and malaria together accounted for $11.4 \%$ of all disability-adjusted life-years (DALYs) globally and $31.5 \%$ in Africa [1]. Based on these numbers alone, the desire to combat these three diseases has been considerable. But a variety of factors have increased this interest still further. Not least among them is a shifting conceptualization of infectious diseases which reclassifies them as a threat to international security. The historical record shows how uncontrolled infectious diseases have been critical in the rise and fall of human societies, from the annihilation of Native Americans to the fall of the Byzantine Empire [2]. Present-day ecological changes such as the rise of mega-cities, the ease of international transport, and the destruction of the natural environment continue to increase the infectious disease burden. Coupled with increasing social inequalities, these global shifts may overwhelm states' capacities for governance and economic growth, and exacerbate the threat of intra- or inter-state conflict $[3,4]$. These dangers prompted the United $\mathrm{Na}-$ tions Security Council to convene an unprecedented session on the threat to Sub-Saharan Africa of HIV/AIDS in January 2000, and prompted the Clinton administration in the United States to appoint a National Science Council on [the security threat posed by] Emerging and Re-Emerging Infectious Diseases. Clinton himself publicly declared AIDS an international security threat at a World AIDS Day commemoration in December 2000 [5].
Another motivation for high-level engagement around AIDS, tuberculosis and malaria relates to domestic disease control concerns. For instance, in most developed countries, tuberculosis is predominantly a disease of the foreign-born, albeit with a notable disease burden among urban disenfranchised and other poor communities. In such settings, it makes far more sense both economically and in terms of public health to 'turn off the tap' of disease burden by controlling tuberculosis at a global level than to 'mop' the global tide of infectious disease through the screening and management of individual patients [6]. There is increasing recognition of the need to broaden horizons beyond our borders and to acknowledge that global forces and international policy shape the disease patterns of our domestic populations.

Finally, a moral-rational model of 'global public goods' has recently been advanced, which urges us to reconcieve the benefits of infectious disease control in the developing world as a common good with benefits for all humanity. Global public goods are 'non-excludable' inputs to the public domain which by definition are available for all to enjoy. 'Enlightened self-interest' is one way of understanding of how one's own well-being is intrinsically tied to that of one's neighbours, but for many, the gross health inequalities between the industrialized and developing world have become intolerable on purely ethical and moral grounds [7].

\section{Discussion \\ The Policy Context: Vertical Disease Control Programs vs. Horizontal Approaches}

Traditionally, there are two general approaches to disease control: 'vertical' disease-specific programs which are independent of the rest of the health care system, and 'horizontal', broader-based approaches to improving health. Vertical control programs are exemplified by the standardized public health approach to TB. In the wake of skyrocketing ТВ rates around the world and the WHO's ensuing declaration of TB as a "global public health emergency" in 1993, international authorities have rallied around a public health package involving directly-observed therapy, short-course (DOTS) as an absolute requirement for control of the disease $[8,9]$. DOTS has achieved good results in numerous settings around the world $[10,11]$.

A similar vertical approach to disease management has been recently proposed for HIV/AIDS as well, calling for centralized, national programs for the delivery of antiretrovirals in the developing world, either alongside or directly integrated with existing $\mathrm{TB}$ programs [12]. The strength of such vertical mechanisms is in the attention paid to all aspects of disease control, spanning the continuum from prevention to treatment and follow-up, and from government commitment to standardized clinical 
care. Indeed, the text of the recent United Nations General Assembly Special Session (UNGASS) Declaration of Commitment on HIV/AIDS addresses a wide array of HIV-related imperatives ranging from clinical prevention and treatment to human rights, from socioeconomic impact to research and development [13]. The fierce commitment of such programs' proponents offers inspiration and hope to those who refuse to 'write off' the health challenges of the developing world as unsustainably expensive or not 'cost effective'.

Vertical programs are not without their critics, however. Often, they are seen as focussing too exclusively on one health problem while unjustly ignoring others. In investing solely in one disease, they may fail to build local capacities to foster broader health benefits. In particular, DOTS vertical programming has received a wealth of criticism, though generally for reasons specific to TB-DOTS programs. For instance, observers of operational research on DOTS have commented that there is a lack of standardization regarding the exact program inputs in studies reporting on DOTS program successes [14]. Foucauldian critiques consider the program's fixation on 'supervised swallowing' to be dehumanizing and authoritarian [15]. Of great practical consideration, there is widespread concern that DOTS may simply not be attainable in resourcepoor settings. In fact, two randomized controlled trials comparing DOTS with self-supervision, family supervision, or both, failed to demonstrate the superiority of direct observation by a health worker, suggesting that cheaper and more convenient forms of treatment supervision than DOTS merit consideration. The first trial, conducted in South Africa, reported greater treatment success among self-supervised patients $(60 \%)$ than DOTS patients (54\%) [15]. The second, conducted in Pakistan, revealed similar results for all forms of direct observation: $64 \%$ cure rates for DOTS, 55\% for family supervision, and $62 \%$ for self-supervision [16]. Suggestions that downplay the supervisory role of health care professional have thus emerged, arguing that the counselling and personal support capacities of treatment observers are more important factors in the program's success $[17,18]$.

More complex analyses of tuberculosis control point to the insidious emergence of multi-drug resistant tuberculosis (MDRTB) as both evidence and predictor of DOTS' shortcomings. MDRTB refers to strains of the bacterium which are resistant to at least isoniazid and rifampin, the two drugs at the foundation of standard DOTS therapy (though strains may be resistant to other drugs as well). Mathematical modeling [19], medical anthropological studies [20], and epidemiological surveys in at least 6 countries [21] demonstrate how the formulaic application of DOTS in the era of multidrug resistance can fuel a growing epidemic of MDRTB. The failure of vertical pro- gramming, it is argued, lies in the inadequacy of underlying health care systems and, more fundamentally, in the virulence of a globalizing world system which marginalizes the poor $[22,23]$. Despite its virtues, broader approaches are clearly needed which address the complex ways in which poverty and inadequate access breed resistance.

An alternative framework for addressing these systemic forces is a 'horizontal' approach to public health, in which emphasis is placed on basic needs and essential health infrastructure. Indeed, it is widely pointed out that throughout the world, 95\% of people living with HIV/AIDS lack access to basic health care services [24]. Since 1978, one popular way of conceiving this approach is through the promotion of Primary Health Care, the focus of an oft-cited WHO International Conference in Alma-Ata, USSR, in that year [25]. The Declaration of Alma-Ata advocates a multifactorial approach involving health education, an adequate food supply, nutrition, safe water and sanitation, maternal and child health, immunization, disease control and prevention, and the provision of essential drugs.

More recently, the international development community has promoted another horizontal approach to known as a 'Sector Investment Program' or, when applied to the health domain, a 'Sector-Wide Approach' (SWAp). This technique, first proposed by the World Bank in 1995 and pioneered in several countries in Sub-Saharan Africa and South Asia, represents a novel approach to 'development' and 'aid' which builds on the well-described failures of project-oriented funding and structural adjustment program approaches [26-28].

SWAps involve a series of crucial steps that differentiate them from previous models. First, agreement is reached in advance among local government, donors, and locally active non-governmental organizations (NGOs) on a clear set of priorities within a given sector (e.g., the health sector). Donor monies are then pooled into a transparentlymonitored, locally-controlled fund, which is used to finance sector activities in order of pre-specified priority. A SWAp thereby does away with the fragmentation and inefficiency of project-by-project, donor-by-donor approaches, in favour of a coherent, mutually-agreed upon policy framework which is under local, rather than donor, control. Poverty reduction and the rational prioritization of development initiatives are key components of the strategy, making it a potentially effective mechanism for addressing horizontal public health goals. Present experience with SWAps has been limited to only a few African and Asian countries, and tensions remain over the changes demanded of funding agencies (e.g., financing of recurrent rather than one-time expenditures), the balance between government and NGO priorities, and other key 
areas [28]. Nevertheless, results have been encouraging thus far, and their potential to broadly address the health problems of the global South remains significant.

But horizontal approaches, too, have their limitations. Since the Alma-Ata commitment to 'Health for All by the year 2000' was announced, for instance, HIV/AIDS has emerged and flourished, while the continuing death tolls of malaria and tuberculosis rates seem to demand specific attention. There is also widespread concern that vertical, disease-specific programs - notwithstanding their own inadequacies - will not fit into SWAp frameworks at all. Indeed, a recent report from Zambia describes how SWAp policy reform in that country led to the collapse of its previously effective tuberculosis program [29].

The challenge ahead for the control of HIV, tuberculosis and malaria will be in achieving an appropriate balance between targeted interventions for these major killers and broader programs targeting the underlying inadequacies which predispose people to poor health. As argued recently in the Bulletin of the World Health Organization,

The two approaches are not in opposition to each other and a false choice between vertical and horizontal approaches should not threaten international cooperation for disease control, nor should disease control be promoted at the cost of health sector development or of focusing on non-communicable diseases ... To accomplish targeted health-policy outcomes, the international community should therefore encourage organizations such as WHO to complement horizontal, health sector programmes with vertical multisector, multilevel initiatives [7].

Disease-specific interventions could, for instance, be used as a springboard for investments into the health care systems which buttress them. In the realm of HIV control, for instance, targeted efforts to decrease mother-to-child HIV transmission via $\mathrm{AZT} /$ nevirapine prophylaxis should be conceived not as stand-alone interventions, but rather as integral parts of a maternal and child health care package [30]. Such an integrated approach would ideally include disease-specific interventions such as antiretroviral therapy for the mother, voluntary counseling testing for her sexual/blood contacts, as well as psychosocial support. At the same time, it would strengthen health infrastructure through pre- and postnatal care, STD counseling and screening, nutritional supplementation and family planning.

In fact, experience with integrating HIV- and tuberculosisspecific interventions into broader community health programs has already been reported from the developing world. Through its 'HIV Equity Initiative' in rural Haiti, one group has employed community health workers, so- cial and economic support for families, and simplified clinical treatment algorithms to integrate vertical HIV prophylaxis and highly-active antiretroviral therapy (HAART) into an existing community clinic [31].

The same group has also advocated a newer vertical approach to MDRTB known as DOTS - Plus, a standard DOTS protocol enhanced by individually-tailored pharmacotherapy [32]. While critics may contend that this is too costly and technically demanding for a resource-poor setting, its advocates contend that the treatment of MDRTB is the only rational and morally acceptable medical and public health response to this phenomenon. They and others have demonstrated its feasibility in rural Haiti, the slums of Peru and urban Turkey $[20,33,34]$, and have successfully integrated the program into a communitybased health care setting which addresses patients' broader health needs. Further, to bolster this aggressive approach, encouraging progress has been made in negotiating price reductions for second line anti-tuberculous drugs through a WHO-convened Working Group and its 'Green Light Committee' [35].

Clearly, vertical disease control programs must be complemented by broader, horizontal approaches to health care and health infrastructure if AIDS, tuberculosis and malaria are to be controlled. By extension, policy makers must consider the broader socioeconomic inputs to health if outcomes are to be improved - an approach which may require higher-level political commitments and systemic, structural change.

\section{The Global Fund: A Golden Opportunity?}

The GFATM is an international financing initiative representing the new-found determination of the international community to address the health impact of the three diseases. The Fund was born out of discussions at the Okinawa G8 Summit in July 2000, and was made concrete by UN Secretary General Kofi Annan's call to action in April 2001. Bolstered by the subsequent United Nations General Assembly Special Session on HIV/AIDS (UNGASS) in June 2001, and by the G8 Summit in Genoa, July 2001, the Fund has become operational in a remarkably short period of time. After a rigorous selection process, the Fund announced its first round of grants in April 2002 [36], through which $\$ 616$ million will be dispersed over two years [37].

Two issues are of particular interest in this granting process. The first relates to how the Fund tackled the question of balancing vertical, disease-specific 'product support' against horizontal health systems support. Though its name suggests a distinctly vertical approach, the Fund's stated intentions are to "address the three diseases in ways that will contribute to strengthening health systems". It 
aims to support proposals which "build on, complement and coordinate with existing ... national policies, priorities and partnerships, including Poverty Reduction Strategies and sector-wide approaches" [36]. On paper, its list of approved projects from the April 2002 round of grants appears to have favoured disease-specific programming, including comprehensive 'prevention and control' strategies, the social marketing of disease prevention, DOTS expansion programs, and a few cases of product support (eg. bednets in Tanzania, antiretrovirals in Nigeria) [36].

One strategy the Fund has employed to ensure a broad consensus on an individual country's programming is to require that every application be done through a partnership that includes representatives from governments, civil society, and people affected by the diseases. The goal of these Country Coordinating Mechanisms (CCMs) is to improve coordination of their activities and to avoid duplication [36]. But the extent to which the GFATM lives true to its goal of building broad-based health systems thus remains to be seen.

The Global Alliance for Vaccines and Immunizations, another global body active in the arena of international health, appears to provide a model for balancing these approaches:

The alliance's executive director is reported to have said that an optimum balance might be $60 \%$ of funds for new vaccines and $40 \%$ for strengthening immunization services. To encourage recipients to meet the targets set, additional funds for strengthening health systems will be released only once the countries have reached higher levels of immunization coverage [38].

But ironically, "failure to meet targets could indicate the need for greater support to weak health systems rather than withholding of funds" [38].

Investing in horizontal programs for developing health systems would not only provide much-needed basic services for individuals suffering from these and other diseases at present, but would also lay essential groundwork for the future delivery of targeted interventions such as medications and immunizations, once they become available. The way ahead lies in fostering innovative solutions that integrate vertical, disease-specific programming for AIDS, tuberculosis and malaria with much-needed health systems support.

The second issue of interest in the Fund's granting process was how the Fund balanced treatment programs with prevention programs in allocating its monies. It is now widely recognized that antiretroviral treatment is a cornerstone of HIV/AIDS control that must not play second fiddle to prevention, and that treatment for HIV plays an important role in controlling tuberculosis and malaria infection as well [39]. In its official call for funding applications in January, the GFATM articulated a commitment to the "prevention, treatment, care and support of the infected and directly affected" [36], and in his July 2002 speech to the XIV International AIDS Conference in Barcelona, executive director Richard Feachem reiterated this dedication. He stated that the first round of grants "will double the current number of people receiving Highly Active AntiRetroviral Therapy (HAART) in the developing world and in Africa HAART recipients will increase six fold as a result of these commitments" [40].

But as Feachem himself acknowledges, these achievements are "nothing like enough". The inadequacy may largely be due to the continual reluctance of industrialized countries to finance treatment programs - particularly for expensive antiretroviral (ARV) therapy. Indeed, officials from Malawi and other countries were allegedly encouraged by donor countries to remove a treatment component from their GFATM proposal [37]. Yet at around the same time, the WHO made the groundbreaking move of adding ARVs to its Essential Medicines List [41].

The debate over funding medicines encompasses a deeper issue, about balancing the potentially limitless need for costly pharmaceuticals with the financial interests of the pharmaceutical companies that manufacture them. Macroeconomic analysis by the United Kingdom's Performance and Innovation Unit (UKPIU) [24] asserts that in order to establish any reasonable hope for the widespread availability of medications, vaccines and other health products for these diseases in the future, the Fund should provide a secure market for affordably-priced goods. Further, it should signal this commitment through advancepurchase commitments. The document argues that it is only through a willingness to cover the costs of manufacture, as well as the financial risks of research, that the global community can hope to drive research and development into essential medicines and vaccines.

But wherein lies the balance of power in a system which lays corporate bottom lines at the foundation of a global effort to combat the diseases of poverty? Half the members of the commission that wrote the UKPIU report are from the pharmaceutical industry. By no means does this invalidate their findings - indeed, the report applies sound economic theory in reaching rational, pragmatic conclusions. But already, the public sector provides most of the market for pharmaceutical products, through public health insurance schemes. Furthermore, a review of the chemotherapeutic agents developed by the pharmaceutical industry over the past 25 years reveals how despite in- 
creased protection in the form of extended patent durations, the industry has not shown a concomitant increase in innovation [42]. The lack of new medicines for neglected diseases of the world's poor populations is palpable: of 1393 new chemical entities marketed over this time period, only 16 were for tropical diseases and tuberculosis [42]. Taken together, these arguments form the basis for calls for innovative new mechanisms for improving the development of and access to therapies for major infectious diseases.

Contrasting the views of industry are the recommendations of another global constituency with vested interests in the GFATM's design - namely, the health NGO sector. Deeply concerned about the Fund becoming a mere 'pharmaceutical industry subsidy' [43], NGOs have made passionate pleas that priority be given to finding the most affordable, effective treatment available when GFATM monies are used to purchase medications. As observed by Director of Médecins Sans Frontières' Access to Essential Medicines Campaign Bernard Pecoul, an explicit statement of this commitment is conspicuously missing from the Fund's official documentation [44].

Practically speaking, the Fund must ensure that expensive, brand-name antiretroviral drugs are not blindly purchased where legal mechanisms could allow the purchase of up to three times the quantity of an equally efficacious generic version of the same medications. In the excitement over ensuring that large-scale efforts to treat the three diseases maintain adequate respect for intellectual property rights, potential beneficiaries must be explicitly reminded that obtaining generic and branded medicines through alternative mechanisms such as compulsory licensing and parallel import arrangements are entirely consistent with the Trade-Related Aspects of Intellectual Property Rights agreement (TRIPS) [45]. The legality of these measures was explicitly agreed to at the WTO's 2001 meeting in Doha, Qatar. Paragraph four of the declaration reads: "We agree that the TRIPS Agreement does not and should not prevent Members from taking measures to protect public health. Accordingly, while reiterating our commitments to the TRIPS Agreement, we affirm that the Agreement can and should be interpreted and implemented in a manner supportive of WTO Members' right to protect public health and, in particular, to promote access to medicines for all" [46]. Practical legal experience such as that garnered through Brazil's success with using the mechanism of compulsory licensing to reduce the price of both generic and brand ARVs down should be translated elsewhere, so that potential applicants might gain access to the most affordable quality medicines.

Of relevance to this discussion of pharmaceutical and NGO interests, another set of policy tensions in the
GFATM's history relates to its governance. The very composition of the Fund's Executive Board was under contentious debate in preliminary sectoral consultations by the Fund's Transitional Working Group. Since its inception, the Fund has billed itself as a "public-private partnership", yet consultation with the NGO sector initially recommended that no representatives of the pharmaceutical industry be members of the Board. Meanwhile, the private sector itself asked for more than the proposed two allotted positions on the Fund's 15-person Board, requesting in the interim an additional ex-officio observer seat. For the present, both constituencies retain two Board positions, which will hopefully preserve a balance between private and public perspectives.

\section{The Challenge of Funding the Fund}

The Global Fund represents an important opportunity for visionary leadership and meaningful action towards reducing the horrific tolls of HIV/AIDS, TB and malaria. The challenges which lie ahead for the GFATM lie in fostering and funding innovative projects which integrate vertical approaches with horizontal approaches, and balance preventive programs with treatment. But even beyond these programming dilemmas, how easily will it reach its lofty goals?

A quick survey of the GFATM's progress to date reveals its first major barrier, in the form of grossly inadequate funds. If the international community is truly as committed to stamping out these three diseases as it would have the world believe, it must drastically scale up its financial commitments. At this writing, the fund totals little more than $\$ 2.1$ billion [36] - a relatively paltry sum when compared to a recent report that put the minimum price tag for global HIV control at $\$ 7.5$ billion annually for that disease alone [47]. Commendable shows of leadership have been made by Kofi Annan himself, who initiated the fund by personally donating $\$ 100,000$ of prize money from his Philadelphia Liberty Medal, and by the governments of Sub-Saharan Africa, which set target commitments of $15 \%$ of their annual national budgets to be devoted to health sector improvements for HIV/AIDS at an April 2001 summit in Abuja, Nigeria. But what of the leadership from the G8 countries, out of whose own summits the very idea of the Global Fund first arose?

To date, the G8 have collectively committed about $\$ 1.6$ billion of the $\$ 2.1$ billion total [36]. The Unites States has pledged by far the greatest proportion of this amount, at $\$ 500$ million. But these seemingly impressive dollar figures fall far sufficient of the money needed. At least \$US 1.3 billion each year is required to support basic commodities for prevention and treatment for malaria among vulnerable groups [48]. Thus far, less that \$US 23 million has been awarded by the Fund for Malaria. African coun- 
tries, which represent $90 \%$ of the global malaria burden, gets only \$US 12.7 million [48]. In the wake of post-September 11 anthrax scares, for instance, the 2003 US Homeland Security Budget has proposed $\$ 5.9$ billion to defend against bioterrorism [49]. Similarly, the seemingly astronomical price tag of $\$ 7-10$ billion for HIV/AIDS control is dwarfed by the still more astronomical annual expenditures on military and defense budgets the world over. Global military spending totaled $\$ 1$ trillion in 1990 alone, and industrialized countries spend $5.3 \%$ of GNP on military expenditures each year [23]. In contrast, these same countries spend less than $0.3 \%$ of GNP on overseas development assistance (ODA) each year - far short of their mutually-agreed upon target of $0.7-1.0 \%$ of GNP [23].

A glimmer of hope shone over the weeks leading up to the recent June 2002 G8 Summit in Kananaskis, Canada, where a 'New Partnership for African Development' (NEPAD) was placed high on the agenda. Drafted by African leaders themselves, the proposal's great innovation was that aid spending on the continent would be more reliably spent, since NEPAD required them to pass an African peer review process. But despite the enthusiasm about this attention to Africa, the industrialized countries still failed to make AIDS, tuberculosis and malaria a priority in Kananaskis. UN Envoy on AIDS in Africa Stephen Lewis made this point abundantly clear in his speech to the Alternative Summit that ran parallel to the official G8 proceedings [50]. He notes that while the NEPAD document sets admirable goals (an annual growth rate of 7\% for fifteen years, halving poverty by 2015 , a two-thirds reduction in infant mortality, a $25 \%$ reduction in maternal mortality, and education for all children), none of them are realistically attainable unless the HIV/AIDS pandemic receives the attention it deserves. Yet, NEPAD pays little attention to the disease in its proposals.

The global community must rethink its approach to 'development', with HIV/AIDS and the other major infectious diseases at the core of its analysis. This is precisely the argument of the much-heralded recent WHO Report of the Commission on Macroeconomics and Health. In it, Jeffrey Sachs asserts that

The burden of disease in some low-income regions, especially sub-Saharan Africa, stands as a stark barrier to economic growth and therefore must be addressed frontally and centrally in any comprehensive development strategy. The AIDS pandemic represents a unique challenge of unprecedented urgency and intensity. This single epidemic can undermine Africa's development over the next generation, and may cause tens of millions of deaths in India, China, and other developing countries unless addressed by greatly increased efforts [51].
The importance, then, of combatting AIDS, tuberculosis and malaria has been made clear in the global arena. If global health is truly understood as a 'global public good', the necessary finances must be mobilized by whatever means necessary.

One proposal offers compelling reasons to open up national health budgets to fund health development in the international arena [7]. By this argument, money budgeted for investment in the health of one country's population is just as appropriately spent on global health problems as domestic ones, since the health of the world's populations are so closely intertwined. Regardless of the accounting logistics, it must ultimately be realized that the funds required for the control of AIDS, tuberculosis and malaria do exist, and must be made available through a careful re-examination of funding priorities.

\section{The Way Ahead}

The GFATM holds considerable promise for harnessing true international commitment to addressing the three diseases. But even if the Global Fund attains its massive targets of \$7-10 billion US per year, does it truly have the capacity to mend the damage from diseases so mired in centuries of growing global inequality?

HIV/AIDS, tuberculosis and malaria are diseases that demand consideration of populations' underlying predisposition to disease in the forms of socioeconomic inequality and abject poverty. While the motivations of the international community for addressing the diseases include pragmatic concerns of international security, economic prosperity and domestic health status, they must ultimately include the ethical responsibility to redress gross inequalities. Adequate attention to the systemic forces underlying these infections thus necessitates correspondingly systemic solutions.

As discussed already, not least among these is the need to mobilize far larger sums of money to invest in world health and in redressing social inequalities. For decades, much of Africa has been left to stagnate in a perpetual "poverty trap" [52], in which the state is simply too poor to provide adequate basic living conditions for the population. Infectious diseases are both a cause and a consequence of this lack of health care, education and infrastructure. Direct financial transfers and investment in basic needs in such countries are the only viable solutions to the continent's ongoing health and economic crises.

Hand in hand with this financial commitment is the need to relieve those developing countries with unreasonable debt burdens of these outlandish costs. Debt repayment schedules paralyze national budgets and lock them into paying back unsustainable sums of money to high-in- 
come countries and financial institutions every year. On average, debtor countries pay one and a half times as much in servicing debt as they do on health care [53]. Debt relief is imperative if the Global South's bankrupt governments are ever to address their populations' basic health needs. Economic theory asserts that for a creditor nation, "the outright cancellation of debt becomes ... a necessary part of its foreign policy" if it hopes to promote economic growth as well as its own strategic interests in bankrupt states $[47,52]$.

Similarly, industrialized countries must reform trade policies that create absurd financial barriers to the integration of poor countries' economies into the global marketplace. Import tariffs on many African goods destined for the United States, for examples, can reach levels of up to 33\% - up to 15 times the average US tariff rate of 2\% [54]. Structural barriers such as these clearly impair the capacity of poor countries to attain anything close to equal footing with rich ones in their attempt to bring economic prosperity to their people.

Finally, in our increasingly globalized economic system, the 'right' of transnational corporations to global patent protection for medicines that are almost exclusively sold to the minority in the rich West must become more intimately tied to their international responsibilities, in the form of technology transfer, local capacity building, and investments in basic infrastructure. Nowhere is this more true than for the pharmaceutical industry, where the public sector must play an active role in obliging its private sector partners to invest in research and development for neglected diseases, commit to equitable pricing schemes and participate in technology transfer. It is only by linking rights and responsibilities that we can hope to achieve improved health for all the world's inhabitants.

\section{Summary}

Research abounds which links these glaring inequalities and potential solutions to epidemic infectious diseases. The UNGASS Declaration of Commitment on HIV/AIDS already represents one forum in which the global call for such measures as ODA increases and debt relief has been clearly spelled out [13], and the Commission on Macroeconomics and Health has provided another powerful voice for increased international commitment. The challenge ahead lies in directly transforming research data and our moral obligation into concrete international policy.

HIV/AIDS, TB and malaria are diseases mired in longstanding fundamental inequalities. Structural changes in policy such as a realignment of spending priorities, debt relief, equitable trade policies and a commitment to global corporate responsibility must complement other economic aid mechanisms for improving public health in the future. Achieving an appropriate balance between vertical and horizontal programming and between prevention and treatment strategies are issues to be resolved by the GFATM and other institutions at the programming level. At a more fundamental level, the G8 countries that spearheaded the GFATM initiative must show political and financial leadership in putting these cold, sobering realities at the forefront of the international agenda if their intentions to curb the toll of these three diseases are to be effectively realized.

\section{Competing interests}

None

\section{Authors' contributions}

DT wrote the initial and final drafts of the manuscript. RU and NF provided valuable support and instructive comments on all drafts. All authors read and approved the final manuscript.

Opinions expressed are those of the authors and may not represent the official views of the employing organization.

\section{Acknowledgments}

Dr Upshur is supported by a New Investigator Award from the Canadian Institutes of Health Research and a Research Scholar Award from the Department of Family and Community Medicine, University Of Toronto.

The authors are very grateful to Shari Gruman for her expert assistance in the preparation of the manuscript.

\section{References}

I. World Health Organization World Health Report 2002, [http:// www.who.int/whr/2002/en/]

2. McNeil WH Plagues and Peoples Toronto, Doubleday 1989,

3. Price-Smith AT Contagion and Chaos: Infectious Disease and its effects on Global Security and Development University of Toronto Centre for International Studies Working Paper 1998-00I 1998,

4. National Intelligence Council The Global Infectious Disease Threat and Its Implications for the United States. NIE 99I7D [http://www.odci.gov/cia/publications/nie/report/nie9917d.html] January 2000

5. Ross S Clinton calls AIDS threat to world security Associated Press Newswires 12/01/2000

6. Menzies D Tuberculosis crosses borders Int J Tuberc Lung Dis 2000, 4( I 2):SI53-59

7. Kaul I and Faust M Global public goods and health: taking the agenda forward Bull World Health Organ 200I, 79:869-874

8. World Health Organization, Global Tuberculosis Programme Treatment of Tuberculosis: Guidelines for National Programmes World Health Organization 1997,

9. The World Bank Investing in Health: World Development Report 1993 Oxford, Oxford University Press 1993,

10. Khatri GR and Frieden TR Controlling Tuberculosis in India N Engl J Med 2002, 347: 1420-1425

II. China Tuberculosis Control Collaboration Results of directly observed short-course chemotherapy in 112,842 Chinese patients with smear-positive tuberculosis Lancet 1996, 347:358362

12. Harries AD, Nyangulu DS, Hargreaves NJ, Kaluwa $O$ and Salaniponi FM Preventing antiretroviral anarchy in sub-Saharan Africa Lancet 2001, 358:410-414

13. Health Canada Declaration of Commitment on HIVIAIDS Report on the United Nations General Assembly Special Session (UNGASS) on HIVIAIDS 200I, 
14. Garner P What makes DOT work? Directly observed therapy Lancet 1998, 352:1326-1327

15. Zwarenstein M, Schoeman JH, Vundule C, Lombard CJ and Tatley M Randomised controlled trial of self-supervised and directly observed treatment of tuberculosis Lancet I998, 352: | 340-I 343

16. Walley JD, Khan MA, Newell JN and Khan MH Effectiveness of the direct observation component of DOTS for tuberculosis: a randomised controlled trial in Pakistan Lancet 2001, 357:664669

17. Moore P DOTS: what's in a name Lancet 200I, 357:940

18. Shafer J, Falzon D, Small I, Kittle D and Ford N DOTS in Aral Sea area Lancet 200 I, 358:200 I

19. Blower SM, Small PM and Hopewell PC Control strategies for tuberculosis epidemics: new models for old problems Science 1996, 273:497-500

20. Farmer P Infections and Inequalities: the Modern Plagues Berkeley, University of California Press 1999.

21. Espinal MA, Kim SJ, Suarez PG, Kam KM, Khomenko AG, Migliori GB Baéz J, Kochi A, Dye C and Raviglione MC Standard Short-Course Chemotherapy for Drug-Resistant Tuberculosis: Treatment Outcomes in 6 Countries JAMA 2000, 283:2537-2545

22. Benatar SR Prospects for global health: lessons from tuberculosis Thorax 1995, 50:487-489

23. Benatar SR Respiratory health in a globalizing world Am J Respir Crit Care Med 2001, I 63:1064-1067

24. Performance and Innovation Unit Tackling the Diseases of Poverty: A Report by the PIU [http://www.cabinet-office.gov.uk/innovation/200I/health/healthreport/0I/content0I.htm]

25. International Conference on Primary Health Care Declaration of Alma-Ata [http://www.who.int/hpr/archive/docs/almaata.html]

26. Harrold $P$ and and associates The broad sector approach to investment lending World Bank Discussion Papers, Africa Technical Department Series, no 302, World Bank 1995 ,

27. Cassels $\mathrm{A}$ and Janovsky $\mathrm{K}$ Better health in developing countries: are sector-wide approaches the way of the future? Lancet 1998, 352:1777-1779

28. Peters $A$ and Chao $S$ The sector-wide approach in health: What is it? Where is it leading? Int J Health Plann Mgmt I998, I3: I 77- 190

29. Bosman MC Health sector reform and tuberculosis control: the case of Zambia Int J Tuberc Lung Dis 2000, 4:606-6I4

30. Johns Hopkins University Center for AIDS Research Global Fund to Fight AIDS, Tuberculosis and Malaria (GFTM) Technical Consultation [http://www.globalfundatm.org/publicdoc/ globalAIDSExecSummaryfinal I 105.pdf] October 30-31 200 I

31. Farmer $P$, Léandre F, Mukheriee JS, Claude MS, Nevil P, Smith-Fawzi MC, Koenig SP, Castro A, Becerra MC, Sachs J, Attaran A and Kim JY Community-based approaches to HIV treatment in resource-poor settings Lancet 200I, 358:404-409

32. Farmer $\mathrm{P}$ and $\mathrm{Kim} \mathrm{JY}$ Community based approaches to the control of multidrug resistant tuberculosis: introducing "DOTS plus" BMJ | 998, 3 | 7:67|-674

33. Farmer PE, Furin J and Shin SS The clinical management of multidrug-resistant tuberculosis / Respir Dis 2000, 21:53-56

34. Tahaogl K, Törün T, Sevim T, Ataç G, Kir A, Karasulu L, Özmen I and Kapakli $\mathrm{N}$ The treatment of multidrug-resistant tuberculosis in Turkey N Engl ] Med 200 I, 345: I70- I74

35. Gupta R, Kim JY, Espinal MA, Caudron J-M, Pecoul B, Farmer PE and Raviglione MC Responding to Market Failures in Tuberculosis Control Science 200I, 293: I049-I05 I

36. The Global Fund to Fight AIDS, Tuberculosis and Malaria [http://www.globalfundatm.org/files/ Financial contributions 011002 .htm

37. New York Times "Combating AIDS in the Third World." [ht tp://www.nytimes.com/2002/04/27/opinion/ 27SAT3.html] April 27, 2002

38. Brugha $R$ and Walt $G$ A global health fund: a leap of faith? $B M$ 200I, 323: I52-I54

39. EL Corbett, RW Steketee, ter Kuile FO, AS Latif, A Kamali and RJ Hayes HIV-I/AIDS and the control of other infectious diseases in Africa Lancet 2002, 359:2177-2187

40. Feachem R Senior Lecture, 9 July XIV International AIDS Conference, Barcelona 2002, [http://www.globalfundatm.org/ journalists/speeches/speech Feachem090702.html]

41. World Health Organization [http://www.who.int/medicines/]

42. $\mathrm{P}$ Trouiller, $\mathrm{P}$ Olliaro, E Torreele, J Orbinski, R Laing and $\mathrm{N}$ Ford Drug development for neglected diseases: a deficient mar- ket and a public-health policy failure Lancet 2002, 359:2I882194

43. Ford $\mathrm{N}$ and ' $\mathrm{t}$ Hoen $\mathrm{T}$ The Global Health Fund: moral imperative or industry subsidy? Lancet 200I, 58:578

44. Pecoul B MSF Open Letter to TWG and TSS [http://archives.hst.org.za/bts/msg00053.html]

45. Ellman T, Ford $\mathrm{N}$ and Brugha $\mathrm{R}$ First round of payments from the Global Fund Lancet 2002, 360:262

46. World Trade Organization Doha Ministerial Declaration on the TRIPS Agreement and Public Health, para 4 WTO Doc No WT/ $M I N(0 I) / D E C / 2200 I$

47. Attaran $A$ and Sachs J Defining and refining international donor support for combating the AIDS pandemic Lancet 200I, 357:57-6I

48. Teklehaimanot A and Snow CP Will the Global Fund help roll back malaria in Africa? Lancet 2002, 360:888-889

49. US Department of Homeland Security [http://www.whitehouse.gov/news/releases/2002/02/20020204-2.html]

50. Lewis S Keynote Address, G6B People's Summit, Calgary, Canada 21 June 2002

51. Report of the Commission on Macroeconomics and Health Macroeconomics and Health: Investing in Health for Economic Development, 20 December [http://www3.who.int/whosis/cmh/cmh report/e/ report.cfm?path $=\mathrm{cmh}, \mathrm{cmh}$ report\&language=english] 20 December 2001

52. Sachs J The Strategic Significance of Global Inequality The Washington Quarterly 2001, 24:187-198

53. Editorial Grants, not loans, for the developing world? Lancet 2001, 357:।

54. Froning D Will Debt Relief Really Help? The Washington Quarterly 200I, 24:199-2II

\section{Pre-publication history}

The pre-publication history for this paper can be accessed here:

http://www.biomedcentral.com/1472-698X/3/2/prepub

Publish with BioMed Central and every scientist can read your work free of charge

"BioMed Central will be the most significant development for disseminating the results of biomedical research in our lifetime. "

Sir Paul Nurse, Cancer Research UK

Your research papers will be:

- available free of charge to the entire biomedical community

- peer reviewed and published immediately upon acceptance

- cited in PubMed and archived on PubMed Central

- yours - you keep the copyright

Submit your manuscript here:

http://www.biomedcentral.com/info/publishing_adv.asp
BioMedcentral 